\title{
POLYMERIZATION OF EPOXY RESINS STUDIED BY POSITRON ANNIHILATION
}

\author{
T. SUZUKI ${ }^{a}$, T. HAYASHI ${ }^{b}$ AND Y. ITO ${ }^{c}$ \\ ${ }^{a}$ High Energy Accelerator Research Organization \\ Tskuba, Ibaraki, 305-0801, Japan \\ ${ }^{b}$ Fine Chemicals Research Laboratory, Sumitomo Chemical \\ Tskuba, 300-32, Japan \\ ${ }^{c}$ RCNS, University of Tokyo, Tokai, Ibaraki 319-1106, Japan
}

\begin{abstract}
The polymerization process of epoxy resins (bisphenol-A dicyanate) was studied using positron-annihilation lifetime spectroscopy. The polymerization from monomer to polymer through a polymerization reaction was followed by positron-annihilation lifetime spectroscopy measurements. Resins kept at curing temperatures $\left(120,150\right.$, and $\left.200^{\circ} \mathrm{C}\right)$ changed form from a powder to a solid through a liquid. The size of the intermolecular spaces of the solid samples increased along with the progress of polymerization.

PACS numbers: $78.70 . \mathrm{Bj}, 83.80 . \mathrm{Cq}$
\end{abstract}

\section{Introduction}

Many types of thermosetting resins have been developed for industrial uses, and have contributed to the development of modern advanced industries. Especially, they are extensively used as an encapsulating material for integral circuits (ICs) and multi-layered printed wiring boards.

These materials are expected to ensure non-stop operation of IC for many years, even under a severe environment (high temperature, high humidity, etc.). In order to assure long-term operation, the hygroscopic property must be kept low. The diffusion of moisture in a polymer depends on the size of the intermolecular spaces and, hence, in order to develop resins it is important to obtain information about the intermolecular spaces. From the point of view of the intermolecular space, positron-annihilation lifetime spectroscopy (PALS) is an important technique and the information can be used together with the characteristics measured by many other types of analytical methods, such as electrical, chemical, and thermo-mechanical analysis (TMA), etc.

We analyzed several types of resins by PALS: bisphenol-A epoxy resins $[1,2]$, novolac epoxy resins [3, 4], and bisphenol-A dicyanate (BADCY) [5, 6]. BADCY has unique characteristics as the size of intermolecular spaces increases with the progress of polymerization. In this report, using PALS, the polymerization process and characteristics of the intermolecular spaces in BADCY samples with different degrees of polymerization are discussed. 


\section{Experimental}

The experimental setup for the polymerization experiment was the same as that described in Ref. [2]. The time resolution of the PALS system was about $0.29 \mathrm{~ns}$ (the full-width at half maximum).

In order to investigate the size of the intermolecular spaces, samples with different degrees of polymerization were prepared as follows.

A sample of $83 \%$ polymerization was prepared by heating for $2 \mathrm{~h}$ at the curing temperature $170^{\circ} \mathrm{C}$ with zinc naphtate catalyst $(0.2 \mathrm{wt} \%)$. The samples of 87,93 , and $95 \%$ were prepared by post-curing of the samples with $83 \%$ polymerization for $2 \mathrm{~h}$ at 200,230 , and $250^{\circ} \mathrm{C}$, respectively.

In these experiment, positron sources of about $1 \mathrm{MBq}(30 \mu \mathrm{Ci})$ sealed in a $7 \mu \mathrm{m}$ thick kapton film were prepared. The PALS spectra were analyzed using PATFIT [7] and MELT (version 3) [8].

\section{Results and díscussion}

\subsection{Polymerization of bisphenol-A dicyanate}

The monomer of BADCY (Fig. 1) is a powder at room temperature. The polymerization proceeds by itself while forming triazine rings at higher temperature than the melting point $\left(T_{\mathrm{m}} \approx 79^{\circ} \mathrm{C}\right)$ without any catalyst by opening the triple bond of cyanate groups $(-\mathrm{OCN})$. The cyanate groups are expected to have a large electron affinity $\approx 3.8 \mathrm{eV}$.

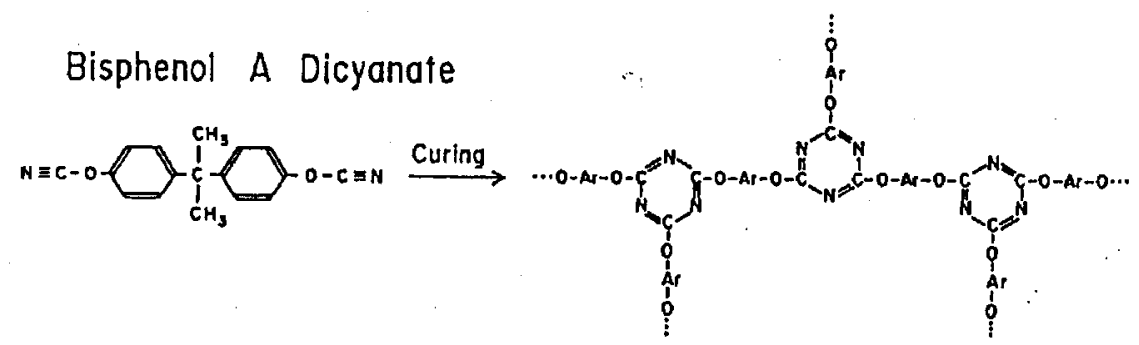

Fig. 1. Chemical structure of bisphenol-A dicyanate and the curing process by forming triazine rings.

The curing reaction of BADCY is an exothermic one and the time required for polymerization depends on the curing temperature. Figure 2 shows the lifetimes $\left(\tau_{3}\right)$ and intensities $\left(I_{3}\right)$ of the long-lived component during the polymerization process at two curing temperatures ((a) 120 and (b) $200^{\circ} \mathrm{C}$ ). Figure $2 \mathrm{a}$ shows the case of temperature being raised from 20 to $120^{\circ} \mathrm{C}$ in $4 \mathrm{~h}$. Below $T_{\mathrm{m}}$, positronium (Ps) formation is suppressed due to the electron affinity of the -OCN groups: thus, the first three-hour points of $I_{3}$ show around 2 to $3 \%$. Then, above $T_{\mathrm{m}}, \mathrm{Ps}_{\mathrm{s}}$ can form bubbles in the liquid state, which can reduce the chemical effect of the-OCN groups, resulting in a sharp increase in $I_{3}$. In the case of Fig. $2 \mathrm{~b} 200^{\circ} \mathrm{C}$, the curing temperature was raised in 10 minutes, and, hence, PALS of the first point was taken in a mixture of powder and liquid. $\tau_{3}$ reached a constant final value in $15 \mathrm{~h}$. 


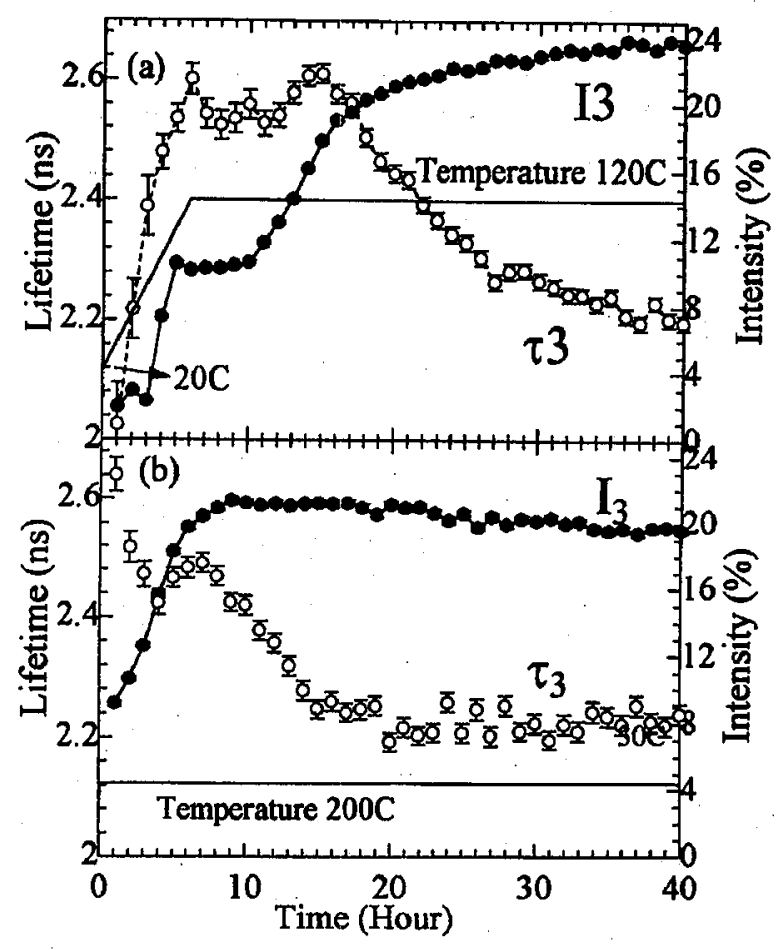

Fig. 2. Polymerization process measured by positron annihilation at two curing temperatures: (a) $120^{\circ} \mathrm{C}$ and (b) $200^{\circ} \mathrm{C}$.

The degree of polymerization can be measured using the IR spectra of the -OCN groups, which is related to the consumption of the -OCN groups by forming triazine rings. Figure 3 shows the degree of polymerization versus the curing time for two curing temperatures, (a) $200^{\circ} \mathrm{C} \mathrm{[9]} \mathrm{and} \mathrm{(b)} 150^{\circ} \mathrm{C}$ [6]. Although, after $30 \mathrm{~h}, 92 \%$ polymerization is achieved in the case of $200^{\circ} \mathrm{C}$, it is only $36 \%$ polymerization for $150^{\circ} \mathrm{C}$. After a curing time of $150 \mathrm{~h}, 84 \%$ polymerization was achieved for $150^{\circ} \mathrm{C}[6]$. The degree of polymerization is expected to be much smaller for $120^{\circ} \mathrm{C}$.

A detailed discussion about the polymerization of BADCY at $150^{\circ} \mathrm{C}$ has already been presented in Ref. [6]. Figure 4 shows the lifetime distributions of the long-lived component analyzed by MELT for the PALS spectra [6] obtained during polymerization at a curing temperature of $150^{\circ} \mathrm{C}$. There are two groups of distribution sets observed within $50 \mathrm{~h}$ : the first group contains the distribution from $3 \mathrm{~h}$ to $30 \mathrm{~h}$ and the second group from $31 \mathrm{~h}$ to $50 \mathrm{~h}$. This graph suggests that there is a discrete transition in the distribution during polymerization between 30 and $31 \mathrm{~h}$. This may be explained by the balance between the Ps pressure in bubbles and the surface tension of resins. As the polymerization proceeds, the surface tension of resins in the liquid state increases; then, the Ps pressure cannot hold the size of the bubble beyond a certain surface tension. The first and second groups of the lifetime distribution are considered to correspond to bubbles formed in liquid with low and high viscosity, respectively. 


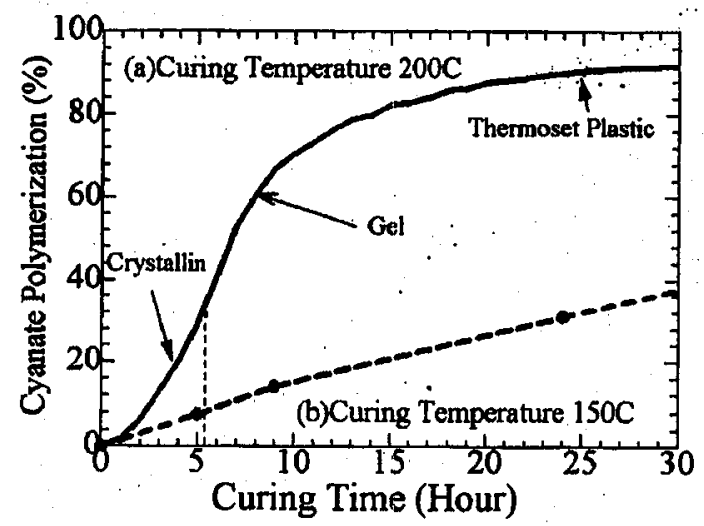

Fig. 3. Degree of polymerization versus time at two curing temperatures: (a) $200^{\circ} \mathrm{C}$ and (b) $150^{\circ} \mathrm{C}[6]$.

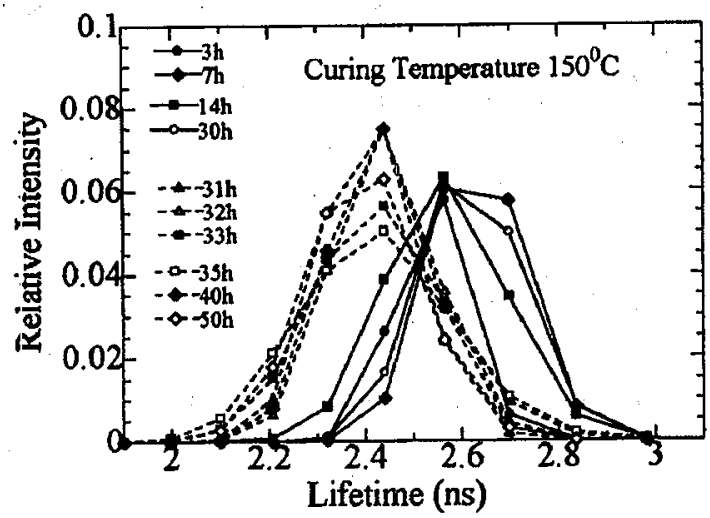

Fig. 4. Lifetime distributions of the long-lived component from the PAL spectra obtained during polymerization at a curing temperature of $150^{\circ} \mathrm{C}[6]$. The distribution was analyzed by MELT [8].

Since the polymerization reaction rate depends on the curing temperature as discussed above, in the case of the curing temperature $120^{\circ} \mathrm{C}$, the transition occurred slowly from the first group to the second group and the clear transition in the group was not observed.

\subsection{Temperature dependence of solid bisphenol-A dicyanate}

PALS measurements were conducted for samples with $c a .84 \%$ polymerization (Fig. 5), which was solidified by heating BADCY powder at $150^{\circ} \mathrm{C}$ for $140 \mathrm{~h}$. Figure 5 shows a large decrease in $\tau_{3}$ and $I_{3}$ at around $210^{\circ} \mathrm{C}$. This indicates that a sample with ca. $84 \%$ polymerization has a heat distortion temperature (HDT) of around $210^{\circ} \mathrm{C}$ : the molecular structures of the samples heated above HDT can change the spatial configuration to make enough space to form triazine rings, and then the polymerization reaction can commence by consuming the -OCN groups. 


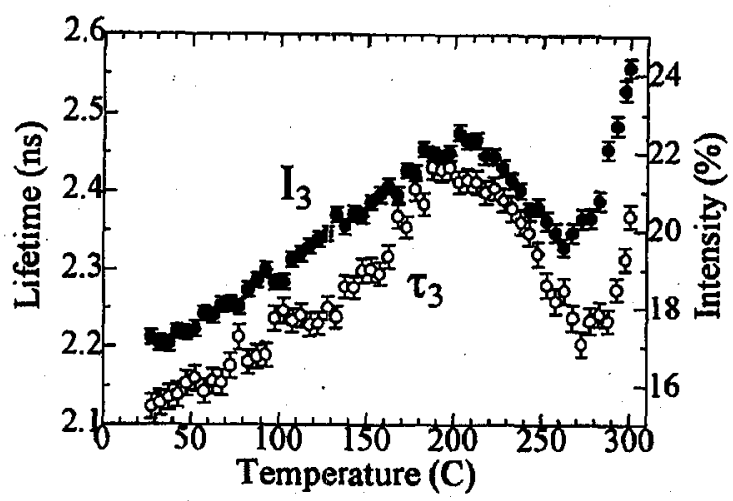

Fig. 5. Intensities $\left(I_{3}\right)$ and lifetimes $\left(\tau_{3}\right)$ versus the post curing temperature for BADCY samples of $c a .84 \%$ polymerization. The temperature was raised by $5^{\circ} \mathrm{C} / \mathrm{h}$.

Above $270^{\circ} \mathrm{C}$ a sharp increase in $\tau_{3}$ and $I_{3}$ was observed; this may have been caused by the following two reasons: (1) further polymerization proceeded by increasing the post-curing temperature from $210^{\circ} \mathrm{C}$ to $300^{\circ} \mathrm{C}$ and the new HDT for fully cured samples was around $260^{\circ} \mathrm{C}[9] ;(2)$ since the thermal degradation temperature of $\mathrm{BADCY}$ is around $285^{\circ} \mathrm{C}$ [9], some parts of the molecular structure may be destructed.

\subsection{Intermolecular spaces along with polymerization}

The increase in the specific volume with increasing polymerization has been reported for BADCY [9]. This was analyzed by PALS, as shown in Fig. 6. The lifetime distribution shifts towards the longer lifetime direction and the width of the distribution becomes narrower at higher polymerization. This indicates that, by increasing polymerization from $83 \%$ to $95 \%$, the intermolecular spaces expand

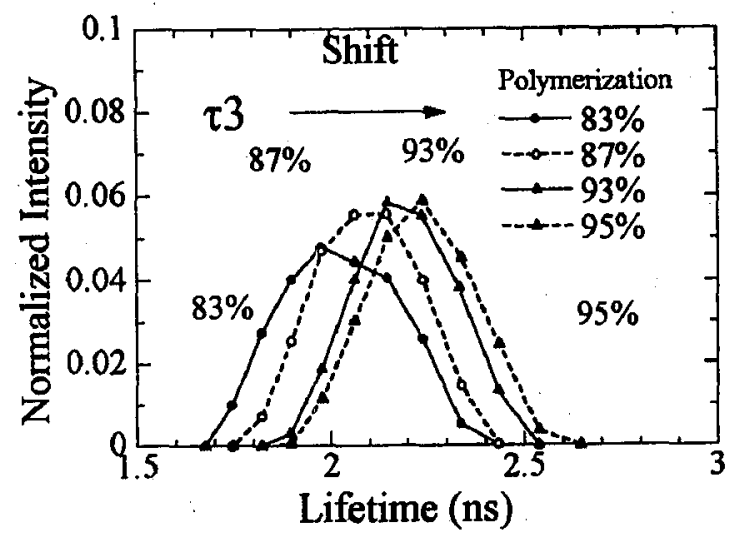

Fig. 6. Lifetime distribution for four kinds of BADCY samples of different degrees of polymerization. 
the size by about $10 \%$; the increase in the specific volume for the increase in the polymerization has been reported to be about $1 \%$ [9].

\section{Conclusion}

The polymerization process of BADCY and the characteristics of solid BADCY samples with different degrees of polymerization were investigated by PALS. During polymerization at $150^{\circ} \mathrm{C}$, the lifetime distribution shows a discrete change, which may be explained by a change in the viscosity. The increase in the specific volume with polymerization was observed as the increase in the lifetime of the long-lived component. The change in the lifetime was 10 times larger than that of specific volume. Thus PALS is a useful technique to analyze characteristics of polymers from the point of view of the intermolecular spaces.

\section{Acknowledgment}

This work was supported by the Grant-in-Aid in Scientific Research by the Japanese Ministry of Education, Culture, Sports and Science. The author would like to thank Sumitomo Chemical Co. Ltd. for the sample preparation.

\section{References}

[1] T. Suzuki, Y. Oki, M. Numajiri, T. Miura, K. Kondo, S. Fujita, Y. Ito, Mater. Sci. Forum 105-110, 1725 (1992).

[2] T. Suzuki, Y. Oki, M. Numajiri, T. Miura, K. Kondo, Y. Ito, Polymer 34, 1361 (1993).

[3] T. Suzuki, Y. Oki, M. Numajiri, T. Miura, K. Kondo, Y. Ito, Y. Shiomi, J. Appl. Polym. Sci. 49, 1921 (1993).

[4] T. Suzuki, Y. Oki, M. Numajiri, T. Miura, K. Kondo, Y. Shiomi, Y. Ito, Polymer 37, 3025 (1996).

[5] T. Suzuki, Y. Oki, M. Numajiri, T. Miura, K. Kondo, Y. Ueda, Y. Shiomi, Y. Ito, Mater. Sci. Forum 175-178, 785 (1995).

[6] T. Suzuki, Y. Oki, M. Numajiri, T. Miura, K. Kondo, H. Nakamura, T. Hayashi, Y. Ito, J. Radioanalytical Nucl. Chem. 210, 555 (1996).

[7] P. Kirkegaard, M. Eldrup, O.E. Mogensen, N. Pedersen, Comput. Phys. Commun. 23, 307 (1981), PATFIT 88, Ris $\varnothing-\mathrm{M}-2740$ (1989 version).

[8] A. Shukla, M. Peter, L. Hoffmann, Nucl. Instrum. Methods Phys. Res. A 335, 310 (1993).

[9] D.A. Shimp, Spring Meeting of the American Chemical Society, New York 1986, PMSE Preprints, 1986, p. 107. 